\title{
Liste des figures et des tableaux
}

\section{Figures}

Figure 1 : Processus schématique de maîtrise de la corrosion $\ldots \ldots \ldots \ldots \ldots 3$

Figure 2 : Objectifs du monitoring de la corrosion $\ldots \ldots \ldots \ldots \ldots \ldots \ldots$

Figure 3 : Liste des informations utiles pour établir la localisation et le positionnement des outils . . . . . . . . . . . 23

Figure 4 : Exemple de structure fonctionnelle d'un système de monitoring de la corrosion . . . . . . . . . . . . 27

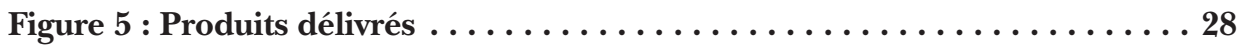

Figure 6 : Schéma d'un réseau de production pétrolière $\ldots \ldots \ldots \ldots \ldots \ldots$

Figure 7 : Exemple de positionnement d'outils pour une ligne horizontale avec écoulement multiphasique. . . . . . . . . . . . . . . 104

Figure 8 : Exemple de positionnement pour une sonde à sable acoustique . . 105

Figure 9 : Seuils $/$ limites, alertes et alarmes. . . . . . . . . . . 108

\section{Tableaux}

Tableau 1 : Étapes de conception du monitoring de la corrosion. . . . . . . 5

Tableau 2 : Exemples d'impact de données opératoires et environnementales sur les choix de monitoring. . . . . . . . . . . . . . 7

Tableau 3 : Exemple de programme de monitoring de la corrosion. . . . . . . . 8

Tableau 4 : Paramètres à surveiller en Exploration - Production . . . . . . . 10

Tableau 5 : Paramètres à surveiller en Raffinage . . . . . . . . . . . 11

Tableau 6 : Points à considérer dans le choix de l'outil $\ldots \ldots \ldots \ldots \ldots \ldots$

Tableau 7 : Solutions de monitoring par mécanismes de corrosion pour l'Exploration - Production. . . . . . . . . . . . 20 
Tableau 8 : Solutions de monitoring par mécanismes de corrosion pour

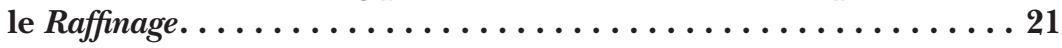

Tableau 9 : Périodicités typiques . . . . . . . . . . . . . . 24

Tableau 10 : Détail des principaux livrables $\ldots \ldots \ldots \ldots \ldots \ldots \ldots \ldots$

Tableau 11 : Classification des actions et mesures de monitoring . . . . . . . 36

Tableau 12 : Exemples de contraintes et de précautions pour la réalisation des mesures.............................. 39

Tableau 13 : Exemples de KPI. . . . . . . . . . . . . . . . 44

Tableau 14 : Exemple d'actions correctives mises en ouvre. . . . . . . . 46

Tableau 15 : Liste des mécanismes d'endommagement . . . . . . . . . 55

Tableau 16 : Classification des probabilités d'occurrence de différents types d'endommagement des installations pétrolières de production. . . . .59

Tableau 17 : Classification des probabilités d'occurrence de différents types d'endommagement en raffinerie . . . . . . . . . 62

Tableau 18 : Avantages et inconvénients des différents positionnements

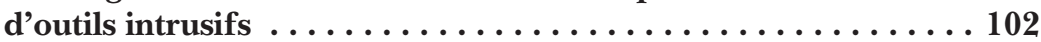

